\title{
Comparison of Ideal Traction Hyperbola Curves with Matlab-Simulink in Vehicles
}

\author{
Hicri Yavuz ${ }^{1 *}$, Hüseyin Bayrakçeken ${ }^{2}$ and F. Emre Aysal ${ }^{2}$ \\ 0000-0001-8427-5164, 0000-0002-1572-4859, 0000-0002-9514-1425 \\ ${ }^{1}$ Department of Motor Vehicles and Transportation Tech., Afyon Vocational School, Kocatepe University, Afyon, 03200, Turkey \\ ${ }^{2}$ Automotive Engineering Department, Faculty of Technology, Kocatepe University, Afyon, 03200, Turkey
}

\begin{abstract}
The gearbox is part of the powertrain that transmits movement from the engine to the wheels. Gears, shafts and auxiliary systems are used in Gearboxes. By using these systems, it is possible to control the movement of the vehicle at the desired tractive effort and vehicle speed in different gear ratios as well as in different direction situations. To increase vehicle performance, it is necessary to obtain curves close to the ideal traction hyperbola.

In this study, vehicle speed and tractive efforts of two different 12 -speed vehicles with the same engine characteristics were calculated with Matlab/Simulink. According to obtaining the results, the tractive effort curves based on vehicle speed were estimated and ideal traction hyperbola curves were formed. The comparison of ideal traction hyperboles for both types of gearboxes showed that the curves have a similar structure.
\end{abstract}

Keywords: Vehicle speed; Tractive effort; Ideal traction hyperbola; Gearbox
* Corresponding author

Hicri Yavuz

hicriyavuz@aku.edu.tr

Adress: Dep. of Motor Vehicles and Transportation Tech., Afyon Vocational School, Kocatepe University, Afyon, Turkey

Tel:+902722182982

Research Article

Manuscript

Received $\quad 17.06 .2020$

Revised $\quad 08.09 .2020$

Accepted $\quad 21.09 .2020$

Doi: 10.30939/ijastech..754210

\section{Introduction}

Gearboxes serve as the drivetrain, which allows the movement of the engine transferred to the wheels at different gear ratio. Since powertrain systems are also important in vehicle design, the engineering in this area provides a driving force in the field of design. [1]. Gearbox systems in vehicles are auxiliary systems for transferring mechanical power from the vehicle engine to provide mechanical energy to the wheels. This system, which is used to transfer power from the engine to the wheels, consists of interconnected gears, shafts and other auxiliary systems and helps to maintain the vehicle's traveling speed and performance. Gearboxes have multiple gear ratios that are capable of shifting as speed changes. In addition to providing forward or backward movement of the vehicle, speed and torque conversions of the power output from the engine are provided at different ratios [2].

The number of gears in the gearboxes should be selected to suit different requirements such as ease of use, production cost and low fuel consumption [3]. Due to fuel consumption, the minimum rates of exhaust emissions are achieved not only by hybridization of the conventional vehicle, but also by accurately determining the gear ratios used in the gearbox. [4].

Due to the significant increase in the number of vehicles in traffic, there was a need to focus on different factors. One of these factors is to increase traffic flow rate, which requires high performance of vehicles [5]. One of the most important criteria to ensure high performance is that the gearbox ratios and the maximum power obtained from the engine return to the exact tractive effort at different travel speeds. This is expressed as the ratio of tractive effort to vehicle speed. According to this ratio, the curve created in all gear situations is called ideal traction hyperbola [6]. The higher driving force obtained from the engine power and the higher torque obtained from the gearbox can be transmitted to the wheels by using a closer hyperbola curve to ideal traction hyperbola curve.

Various gear shift maps have been developed with aim to select optimum gear by adding suitable automatic equipment to manual gearboxes for optimum fuel economy and comfort of vehicles [7]. Thus, at the appropriate time, the gears were changed to approach the ideal traction hyperbola. 
Simulation technology is expected to be used in feasibility studies for the optimization strategies proposed at the design stage to improve fuel efficiency [8]. Experimental testing, which allows the selection of appropriate gear ratios for gearboxes in vehicles to be used for various purposes, such as racing vehicles, and software tools that provide less time and money for various adjustments are also being developed [9]. These software tools should be used not only for such tools but also for different types of tools. Currently researchers are focused on, the number of gears performance and efficiency for modern vehicles [10].

Figure 1 shows the ideal traction hyperbola curve in the tractive effort velocity curve for a four-speed vehicle. The closer drive characteristic speed curves to the ideal traction hyperbola for each gear ratio increased the vehicle performance which means areas a, b, c shown in Figure 1 (which may be increased by the number of gears) decrease. The tractive effort values are the maximum at lower gears, when gears are increase speed tractive effort values are decrease according to first gear.

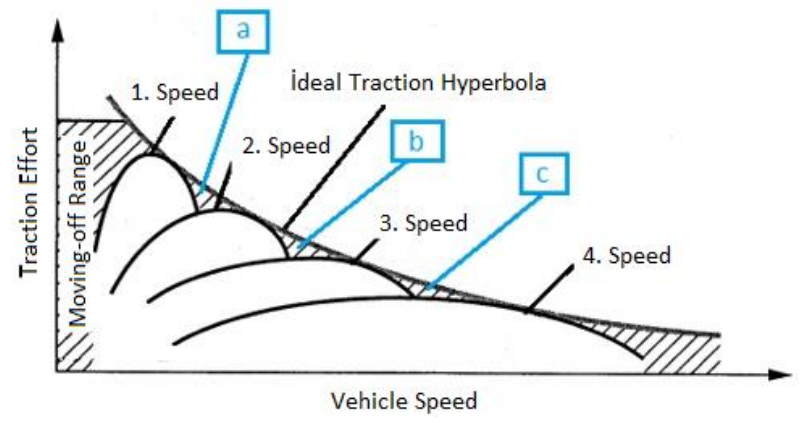

Fig. 1. Traction force- vehicle speed characteristics of a fourspeed vehicle [6]

\section{Material Method}

The maximum power and torque of the vehicle chosen as $286 \mathrm{~kW}$ at $1800 \mathrm{rpm} 1840 \mathrm{Nm}$ at $950 \mathrm{rpm}$ respectively for vehicle speed and tractive effort calculations. Since the ideal traction hyperbola curves of heavy vehicles are important for evaluating their performance, heavy vehicles and suitable gearboxes are taken into consideration in vehicle selection (Fig. 2.)

Features such as moving quickly and carrying the required load are desired. In order to move with the required load, the driving force on the wheels must be at the desired value. Using different gear ratios in gearboxes, the tractive effort on the wheels can be increased or decreased. As shown in Table 1 , the traction force values on the wheels are increased by reducing the number of revolutions taken from the engine by using different gear ratios (Fig. 5-6.).

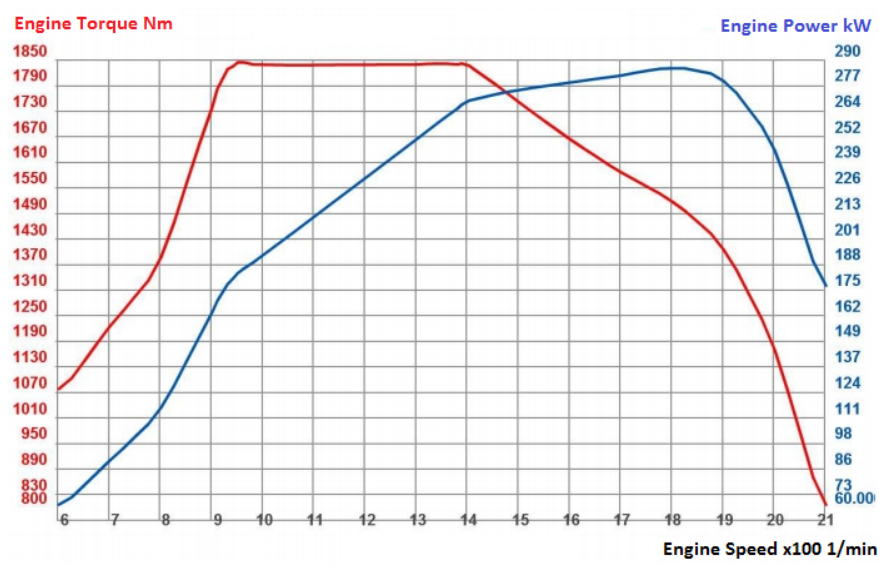

Fig. 2. Engine torque and engine power curve depending on the engine speed of the selected engine [11]

The gearboxes used for vehicle speed and tractive effort calculations will be referred to as type A and B gearboxes. The gear ratios of these gearboxes in different gear conditions are given in Table 1. The forward gear conditions specified in Table 1 are taken into account in the calculations.

Table 1. Gear ratios for type A and type B gearboxes [11, 12]

\begin{tabular}{c|c|c|c|c|c|c|c}
\multicolumn{5}{c|}{ Type A Gearbox } & \multicolumn{4}{c}{ Type B Gearbox } \\
\hline Speed & $\begin{array}{c}\text { Gear } \\
\text { Ratio }\end{array}$ & Speed & $\begin{array}{c}\text { Gear } \\
\text { Ratio }\end{array}$ & Speed & $\begin{array}{c}\text { Gear } \\
\text { Ratio }\end{array}$ & Speed & $\begin{array}{c}\text { Gear } \\
\text { Ratio }\end{array}$ \\
\hline 1. & 14.94 & 7. & 3.44 & 1. & 11.73 & 7. & 2.7 \\
\hline 2. & 11.73 & 8. & 2.7 & 2. & 9.2 & 8. & 2.12 \\
\hline 3. & 9.04 & 9. & 2.08 & 3. & 7.09 & 9. & 1.63 \\
\hline 4. & 7.09 & 10. & 1.63 & 4. & 5.57 & 10. & 1.28 \\
\hline 5. & 5.54 & 11. & 1.27 & 5. & 4.35 & 11. & 1 \\
\hline 6. & 4.35 & 12. & 1 & 6. & 3.41 & 12. & 0.78
\end{tabular}

The symbols and expressions used in the driving force formula set forth in Equation 1 are set forth below [13]. In accordance with this formula, a model for vehicle speed in the Matlab-Simulink program is shown in Figure 3. In the modeling, the traction force calculations were made for each gear condition according to the different engine output torque values shown in the graph in Figure 1. In the modeling made in Matlab-Simulink program, 8 different torque values were taken as 1000-1400-1800-1800-1700-1500-1200-2000 Nm corresponding to the number of revolutions calculated by Equation 2. The wheel radius is $0.51 \mathrm{~m}$, the transmission efficiency is 1 , the gearbox gear ratios are given in Table 1 and the differential gear ratio is 3.36 and the resulting value is shown in the graphs as $\mathrm{kN}$.

$$
F_{t}=\frac{M_{e} \cdot \dot{\mathrm{I}}_{o}}{r_{w}} \dot{\eta}_{t r}
$$


Where; Ft: Tractive Effort [N], Me: Engine Output Torque

[Nm], $\dot{\mathrm{I}}_{0}$ : Total Transmission Ratio [-], ท́tr: Transmission Efficiency [-], rw: Wheel Radius [m] (Fig. 3).

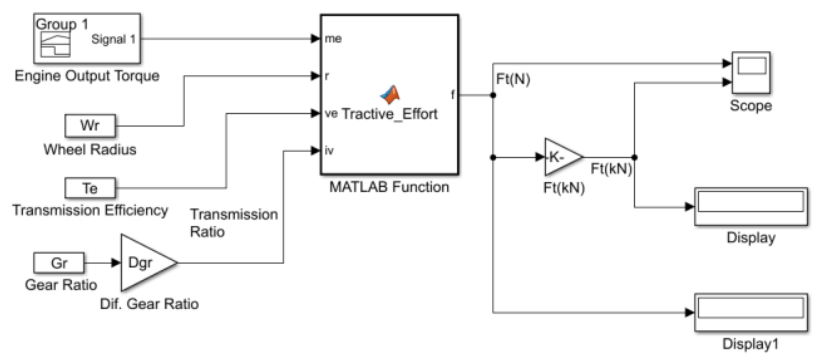

Fig. 3. Tractive effort modeling with Matlab-Simulink

The symbols and expressions used in the vehicle speed formula set forth in Equation 2 are as follows [13]. In accordance with this formula, a model for vehicle speed in the Matlab-Simulink program is shown in Figure 4. Matlab function is arranged according to the different engine speed values indicated in the graph in Figure 1 and vehicle speed calculations are made for each gear case. In the Matlab-Simulink program, 8 different revolution values taken as 600 800-1000-1200-1400-1600-1800-2000 1 / min, wheel radius $0.51 \mathrm{~m}$, slip rate 0 , gearbox gear ratios in table 1 values are taken. The differential gear ratio taken as 3.36 and the results shown in the graphs as $\mathrm{km} / \mathrm{h}$.

$V=\frac{\pi \cdot r_{w} \cdot n_{e}}{30 . \dot{I}_{o}}(1-s)$

Where; V: Vehicle Speed [m / s], rw: Wheel Radius [m], ne: Engine Speed [1 / min], $\dot{I}_{0}$ : Total Transmission Ratio [-], s: Slip Ratio [-] (Fig. 4).

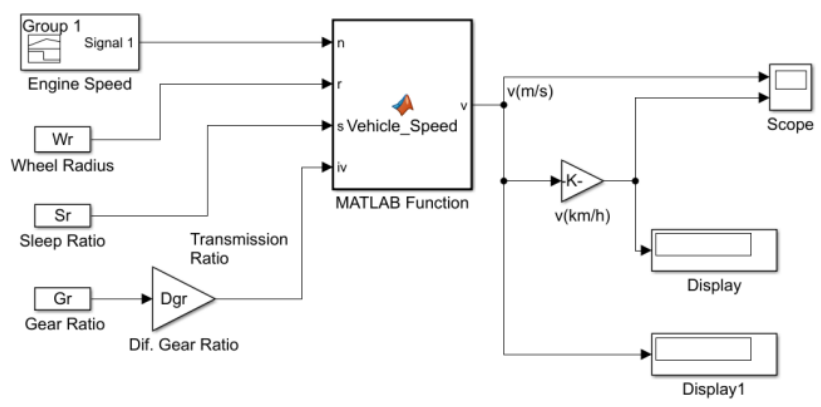

Fig. 4. Modeling of vehicle speed with Matlab-Simulink

\section{Results}

\subsection{Tractive Effort - Speed Characteristics of a Vehicle}

As can be seen in Figure 5, the speed curves of the tractive effort tended to decrease from 1st gear to 12th gear. The tractive effort values are high in lower gear positions and lower in higher gear positions. Vehicle speed values are higher in increasing gear positions and higher in low gear positions. In this gearbox of vehicle $\mathrm{A}$, the maximum speed is achieved in the 12th gear at $114.44 \mathrm{~km} / \mathrm{h}$ at $2000 \mathrm{rpm}$, while the maximum tractive effort is achieved in the 1st gear with 177.17 $\mathrm{kN}$ at $1000-1200 \mathrm{rpm}$.

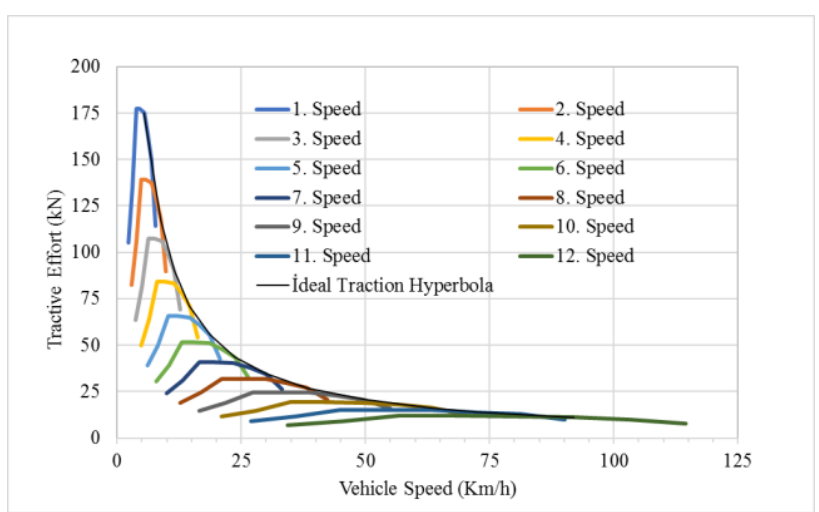

Fig. 5. Vehicle speed - drive characteristics for a 12-speed gearbox of vehicle $\mathrm{A}$

\subsection{Tractive Effort - Speed Characteristics of B Vehicle}

As can be seen in Figure 6, the curves of vehicle B and the curves of vehicle $A$ in different gears have produced a similar driving force velocity curve. In the gearbox of vehicle B, the maximum speed is achieved in the 12th gear with $146.72 \mathrm{~km}$ $/ \mathrm{h}$ at $2000 \mathrm{rpm}$, while the maximum tractive effort is achieved in the 1 st gear with $139.10 \mathrm{kN}$ at $1000-1200 \mathrm{rpm}$.

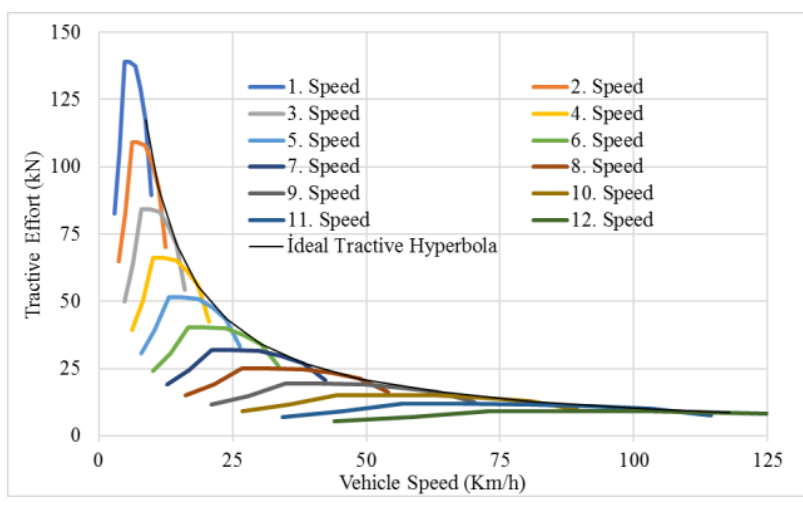

Fig. 6. Vehicle speed - drive characteristics for a 12-speed gearbox of vehicle B 
3.3 Comparison of Ideal Traction Hyperboles for Vehicles $A$ and $B$

When the ideal traction hyperbola curves of vehicles A and $\mathrm{B}$ in Figure 7 are compared, the ideal draw hyperbola curve values of vehicle $A$ are higher than the ideal traction curve of vehicle $B$ and the ideal draw hyperbola curves have drawn a similar curve. The main reason why the driving force values at the same speed are different between the two vehicles is that the gear ratios are different for both gearboxes indicated in Table 1.

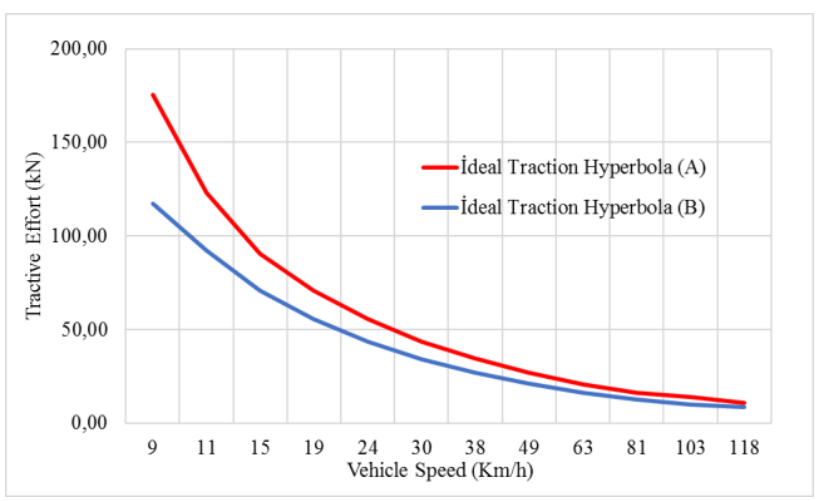

Fig. 7. Comparison of drive-speed characteristics of vehicles with variable gear ratios

\section{Conclusions and Discussion}

In vehicles, the tractive effort and speed values are directly related to factors such as engine torque, transmission ratio wheel radius, engine speed, slip ratio and transmission efficiency. In this study, vehicle speed and tractive effort values of two gearboxes with different transmission ratios of 12 gears for same engine type were calculated by using MatlabSimulink program. Ideal traction hyperbola curves were formed and the differences between them were evaluated. While the maximum and minimum vehicle speed and tractive effort values of vehicle A and B are realized in the same gears, there is variability between values due to the difference in gear ratios.

If the shift curves overlap points in ideal traction hyperbola curves are evaluated for vehicle speed, $33 \%$ in 1st gear, $25 \%$ in 2nd gear, $22 \%$ in all gears in 3rd gear and 10th gear, 28\% in 11 th gear and $12 \%$ in 12 th gear 22 values were higher than vehicle $\mathrm{B}$. When the comparison was made for tractive effort, $39 \%$ in 1st gear, $22 \%$ in 2nd gear and 10th gear, 30\% in 11th gear and $22 \%$ in 12 th gear, B vehicle values were higher than vehicle A.

When the tractive effort curves are compared, vehicle A gives $22 \%$ higher tractive effort for each gear case than vehicle $\mathrm{B}$, whereas the situation is the opposite in vehicle speed, and vehicle B gives a speed value of $22 \%$ higher than vehicle A.
As a result, although the ideal traction hyperbola curves are different depending on the gear ratios, the shapes are similar. In this study, similar ideal traction hyperbola curves were obtained in both types of gearboxes compared. Higher tractive effort in type A gearbox and higher speeds in type B gearbox due to changing gear ratios in gearbox.

\section{References}

[1] Mashadi B. and Crolla D. (2012). Vehicle Powertrain Systems. Wiley.

[2] Suyash, G., Prathamesh D. and Ketan P. (2017). Automobile transmission systems. IJSRD- International Journal for Scientific Research \& Development Vol. 5, ISSN (online): 23210613.

[3] Piotr, B. (2019). A design method of selecting gear ratios in manual transmissions of modern passenger cars. Mechanism and Machine Theory, 132, 133-153.

[4] Karaoglan, M. U., Kuralay, N. S. and Colpan, C. O. (2019). The effect of gear ratios on the exhaust emissions and fuel consumption of a parallel hybrid vehicle powertrain. Journal of Cleaner Production, 210, 1033-1041.

[5] Jozsef, B. and Laszlo, P. (1994). Modern control theory applied to vehicle dynamics. Periodica Polytechnica Ser. Trans. Eng. Vol 24 No:1, 65-80.

[6] Gisbert, L. and Harald, N. (1999). Automotive Transmissions Fundamentals, Selection, Design and Application. Springer.

[7] Vikram, M., Ashok, M., Rakesh, M. and Sushil, R. (2018). Design methodology for gear shift map of automated manual transmission. Materials Today: Proceedings 5, 23898-23907.

[8] Kwangseok, O., Seungjae, Y., Kyungeun, K., Sunghoon, H., Panyoung, K., Jaho, S. and Kyongsu,Y. (2016). Gear ratio and shift schedule optimization of wheel loader transmission for performance and energy efficiency. Automation in Construction 69, 89-101.

[9] Sergio, M, S., Davide, C., Marco, S., Enrico, R. and Emiliano, B. (2006). Gear-Set optimization of a race car. 11th IFAC Symposium on Control in Transportation Systems Delft, The Netherlands, 579-584.

Aysal, F. E., Bayrakçeken. H. and Girgin, Z. (2016). The analysis of level increasement at the vehicle gearboxes. Afyon Kocatepe University Journal of Science and Engineering, 16015901 167-173.

[10] Premium 380.26 6X2 D RJ E5 technical data

[11] Volvo FH FM GearboxATO2612D technical data

[12] Çetinkaya, S. (1999). Taşıt Mekaniği. P 47-48. Nobel. 